\title{
Field-Based Simplified Approach of Evaluating Knee Extensor Muscle Strength and Size in University Freshmen Women
}

\author{
Tomohiro Yasuda
}

\begin{abstract}
Context: Periodic assessment of knee extensor muscle strength and size is important for all ages to evaluate the functional status of individuals and to identify and treat those at risk for mobility problems and frailty; however, it is not fully understood whether these field-based simplified approaches correspond to evaluation in knee extensor muscle strength or size. Objective: To examine the relationship between field-based simplified evaluation approaches and knee extensor muscle strength or size in young women. Design: Experimental. Setting: University research laboratory. Subjects: A total of 62 university freshmen women volunteered to participate in this study. Main Outcome Measures: Knee extensor muscle thickness was measured at the anterior half of thigh length; muscle strength was measured when subjects performed knee extension. Field-based simplified approaches (sit-to-stand, standing long jump, handgrip, and upper leg 50\% [thigh] girth) were also measured. Results: Maximal strength was correlated with thigh girth, handgrip, and standing long jump, but not with the sit-to-stand test. Muscle thickness was correlated with thigh girth and handgrip, but not with standing long jump or the sit-to-stand test. A stepwise multiple-regression analysis was calculated using the predictor thigh girth and standing long jump to predict knee extensor maximal strength $\left(R^{2}=.295\right)$. To predict knee extensor muscle thickness, the predictor thigh girth was calculated $\left(R^{2}=.202\right)$. Conclusions: Knee extensor muscle strength and size could be evaluated by the field-based simplified approaches, in particular by the thigh girth measurement, which may be a major determinant to maintain activities of daily living for healthy young women. However, the 4 field-based simplified approaches appear to be still not of high impact.
\end{abstract}

Keywords: physical fitness test, knee extension, thigh circumference, healthy young women

Maintaining high levels of lower limb muscle strength/size is important to prevent and delay the onset of disability, physical frailty, and dependency. ${ }^{1-3}$ It is generally accepted that the loss of skeletal muscle strength and size with increased age, sarcopenia, is greater in the lower limbs than in the upper limbs $\left(18-88 \mathrm{y}^{4}\right.$; $\left.20-89 \mathrm{y}^{5}\right)$. In addition, recent studies have revealed that sarcopenia is muscle specific and that greater knee extensor muscle loss is found in older adults. ${ }^{6-8}$ Therefore, periodic assessment of knee extensor muscle strength and size is important for all ages to evaluate the functional status of individuals and to identify and treat those at risk for mobility problems and frailty.

In the periodic and field-based simplified approaches, the handgrip strength measurement has been widely used in clinical practice for the assessment of muscle size or strength. ${ }^{9-11}$ However, the handgrip strength is an objective measurement of the upper limb muscle ${ }^{10,12}$; therefore, the field-based simplified approaches for muscle size or strength should likewise be focused on the knee extensor muscles for lower limb muscle assessment. To date, the strength, size, or power for lower body and limb muscles has been frequently evaluated by the use of upper leg $50 \%$ girth, ${ }^{13,14}$ sit-tostand test, ${ }^{15-17}$ or standing long jump measurements, ${ }^{18,19}$ because these measurements are also affordable, portable, simple, and time efficient. Recently, Yasuda and Ichikawa ${ }^{20}$ reported that knee extensor muscle strength and size could be evaluated by the 4 field-based simplified approaches, in particular by the upper leg $50 \%$ girth measurement for healthy young men. On the other hand, a recent study ${ }^{21}$ reported that the prevalence of sarcopenia was higher in women than in men in the young-old. This means that

Yasuda is with the School of Nursing, Seirei Christopher University, Shizuoka, Japan. Yasuda (tomohiro-y@seirei.ac.jp) is corresponding author. these simplified approaches may be particularly attentive for women. However, it is unknown whether these field-based simplified approaches correspond to evaluation in knee extensor muscle strength or size for healthy young women. Thus, the purpose of this study was to examine the relationship between field-based simplified approaches and knee extensor muscle strength or size in healthy young women.

\section{Methods}

A total of 65 Japanese university freshmen women (aged 18-25 y) were recruited through oral communications in a "Sports Practice" course at the School of Nursing in Seirei Christopher University. Before informed consent was obtained, a written description of the purpose of the study and its safety was distributed to potential subjects, along with a lifestyle questionnaire. All subjects were free of overt chronic disease (eg, diabetes, angina, myocardial infarction, cancer, and stroke) as assessed by medical examination report. In addition, musculoskeletal disease and knee joint surgery were also excluded in this study. As a result, 62 university freshmen women were used for data analyses. The principles of the World Medical Association Declaration of Helsinki and the American College of Sports Medicine Guidelines for Use of Human Subjects were adopted in this study. The study was approved by the ethics committee of the School of Nursing in Seirei Christopher University.

Abe et al $^{22}$ revealed that muscle thickness (MT) at the anterior thigh is strongly correlated with anatomical muscle cross-sectional area for knee extensor muscles $(\mathrm{n}=52, r=.91, P<.01)$. Therefore, MT was measured using B-mode ultrasound (ProSound C3CV; Hitachi Aloka System, Tokyo, Japan) at the anterior upper leg (at $50 \%$ between the lateral condyle of the femur and the greater 
trochanter) on the right side of the body. ${ }^{23,24}$ After thigh length measurements using anatomic landmarks described previously, all measurement sites were marked with a marker pen and then midthigh girth (at $50 \%$ of thigh length) was measured using a tape measure. The measurement for MT was taken while the subjects stood quietly with their knees extended and relaxed. A linear transducer with a 10-MHz scanning head (5.5-cm length probe, ProSound C3CV; Hitachi Aloka System) was coated with watersoluble transmission gel to facilitate acoustic contact and to reduce pressure from the scanning head to achieve a clear image. The scanning head was placed on the skin surface of the measurement site using the minimum pressure required. The subcutaneous adipose tissue-muscle interface and muscle-bone interface were identified from the ultrasonic image, and the distance between the 2 interfaces was recorded as MT. Two images from the same site were stored, and the mean value was used for data analysis. The coefficient of variation $(\mathrm{CV})$ of MT measurement from test to retest was $1.3 \%$. The same investigator made all of the ultrasound measurements.

Maximum voluntary isometric contraction (MVIC) of the knee extensors was determined using a knee extension dynamometer (TKK 5710; TAKEI, Tokyo, Japan). The subjects were seated on a chair with their hip joint angle positioned at $\sim 85^{\circ}$ (full extension: $0^{\circ}$ ). The ankle of the right leg was firmly attached to the strain gauge transducer with a chain strap (TKK 5002; TAKEI). After a warm-up consisting of submaximal contractions, the subjects were instructed to perform MVIC knee extension at a knee joint angle of $\sim 90^{\circ}$. Each subject underwent 2 trials, and the best value of the trials was used for analysis. The CV of MVIC measurement from test to retest was $3.1 \%$. The same investigator made all of the MVIC measurements.

Handgrip strength was measured using a factory-calibrated hand dynamometer (TKK 5401; TAKEI). All subjects were instructed to maintain an upright standing position, arms at their side, holding the dynamometer in the right hand with the elbow extended at $180^{\circ}$ without squeezing their arm against their body. The size of the dynamometer's handle was set to a position which the subjects felt comfortable while squeezing the grip. Each subject underwent 2 trials, and the best value of the trials was used for analysis. ${ }^{25}$ The $\mathrm{CV}$ of handgrip strength measurement from test to retest was $4.2 \%$.

All subjects were instructed to perform a long jump from a standing position. Standardized instructions were given to subjects that permitted them to begin the jump with bent knees and swing their arms to assist in the jump. ${ }^{19}$ The length of 3-m hard surface mat (starting and $10-\mathrm{cm}$ interval lines drawn; TOEILIGHT; Touyoutaiki, Kyoto, Japan) was used. The length of jump was determined using drawn lines and a tape measure. Each subject performed 2 trials, and the distance of the best jump was measured, to the nearest $1 \mathrm{~cm}$, from the line to the point where the heel closest to the starting line landed. If the subject fell backward, the distance where the body part closest to the starting line touched the ground was measured as the jump's length. Each subject underwent 2 trials, and the best value of the trials was used for analysis. The CV of standing long jump measurement from test to retest was $2.4 \%$.

A wooden molded chair ( $0.40 \mathrm{~m}$ height and $0.30 \mathrm{~m}$ depth $)$ was used for the sit-to-stand test. The subjects were asked to stand up from a sitting position and then to sit down during 30 seconds as many times as possible. The subjects were instructed to stand up fully and to place their buttocks on the chair in a sitting position between repetitions. ${ }^{17}$ The test started when the examiner said "Go" and stopped after 30 seconds. ${ }^{15}$ Prior to the measurements, practice trials with submaximal effort were performed for positioning and learning of the task. Each subject performed 2 trials with an interval of at least 3 minutes between trials. The highest repetition score was adopted for the individual data. The $\mathrm{CV}$ of the sit-to-stand measurement from test to retest was $8.5 \%$.

Results were expressed as mean (SD) for all variables. All data were analyzed using JMP software v.12.0 for Mac (SAS Institute Inc, Tokyo, Japan). Pearson product correlations of knee extensor MVIC or MT and the simplified approaches were also statistically quantified. A stepwise multiple-regression analysis (method of increasing and decreasing the variables, criterion was set at $P<.05)$ was performed to predict MT or MVIC and physical characteristics (height and weight) and simplified approaches as factors. Consequently, the predicted variables, coefficients, and intercept coefficients were automatically picked out by the JMP software. Statistical significance was set at $P<.05$.

\section{Results}

The physical characteristics and field-based simplified approaches are shown in Table 1. The correlation coefficients between knee extensor muscle strength or size and field-based simplified approaches are shown in Table 2 . There were significant correlations between knee extensor MVIC and upper leg 50\% girth $(P<.01)$, handgrip $(P<.01)$, and standing long jump $(P<.01)$, but not for the sit-to-stand test $(P=.42)$ (Table 2$)$. There were significant correlations between knee extensor MT and upper leg $50 \%$ girth $(P<.01)$ and handgrip $(P=.01)$, but not for the standing long jump $(P=.09)$ or the sit-to-stand test $(P=.88)$ (Table 2$)$.

A stepwise multiple-regression analysis was calculated to the predictor upper leg $50 \%$ girth and standing long jump to predict knee extensor muscle strength $(\mathrm{MVIC}=0.659 \times$ upper leg $50 \%$ girth $+0.114 \times$ standing long jump $-19.51 ; \mathrm{n}=62, R^{2}=.295$,

\section{Table 1 Physical Characteristics, Knee Extensor Muscle Size or Strength, and Field-Based Simplified Approaches in Female University Freshmen}

\begin{tabular}{lcc}
\hline Variable & Mean (SD) & Range \\
\hline Age, y & $18.3(0.4)$ & $18-19$ \\
Height, m & $1.57(0.05)$ & $1.47-1.70$ \\
Weight, kg & $51.0(8.8)$ & $37.2-89.5$ \\
Upper leg length, cm & $36.8(1.4)$ & $33.5-40.0$ \\
Lower leg length, cm & $35.7(1.6)$ & $32.0-39.0$ \\
Body mass index, kg/m ${ }^{2}$ & $20.6(3.2)$ & $15.7-37.0$ \\
Systolic blood pressure, mm Hg & $105(10)$ & $88-132$ \\
Diastolic blood pressure, mm Hg & $61(7)$ & $41-77$ \\
Knee extensor muscle size & & \\
$\quad$ Anterior upper leg MT, cm & $4.6(0.6)$ & $3.5-5.8$ \\
Knee extensor muscle strength & & \\
$\quad$ MVIC, kg & $32.3(6.5)$ & $17.0-46.5$ \\
Field-based simplified approaches & & \\
$\quad$ Handgrip, kg & $26.4(3.8)$ & $18.0-36.5$ \\
$\quad$ Upper leg 50\% girth, cm & $49.1(4.7)$ & $41.1-69.0$ \\
Standing long jump, m & $1.72(0.16)$ & $1.45-2.10$ \\
$\quad$ Sit-to-stand, reps/30 s & $31.1(6.4)$ & $17-44$ \\
\hline
\end{tabular}

Abbreviations: MT, muscle thickness; MVIC, maximum voluntary isometric contraction. Note: $\mathrm{N}=62$. 


\section{Table 2 Pearson's Correlation Coefficients Between Knee Extensor Muscle Strength or Size and Field- Based Simplified Approaches}

\begin{tabular}{lcc}
\hline & \multicolumn{2}{c}{ Pearson's correlation } \\
\cline { 2 - 3 } & MVIC & MT \\
\hline Field-based simplified approaches & & \\
Handgrip & $0.380^{* *}$ & $0.344^{* *}$ \\
Upper leg 50\% girth & $0.466^{* * *}$ & $0.450^{* * *}$ \\
Standing long jump & $0.254^{*}$ & 0.181 \\
Sit-to-stand & 0.066 & 0.009 \\
\hline
\end{tabular}

Abbreviations: MT, muscle thickness; MVIC, maximum voluntary isometric contraction. Note: $\mathrm{N}=62$.

$* P<.05 . * * P<.01 . * * * P<.001$.

$P<.01)$. To predict knee extensor MT, the predictor thigh girth was calculated $(\mathrm{MT}=0.053 \times$ upper leg $50 \%$ girth $+1.984 ; \mathrm{n}=62$, $\left.R^{2}=.202, P<.01\right)$.

\section{Discussion}

The main findings of this study were as follows: (1) knee extensor MVIC was correlated to upper leg 50\% girth, handgrip, and standing long jump, and knee extensor MT was correlated to upper leg 50\% girth and handgrip, and (2) upper leg 50\% girth can predict both knee extensor MVIC and MT in healthy young women.

In general, previous studies reported the relationship between handgrip strength and knee extensor muscle strength/size for middle-aged and older adults. ${ }^{26-28}$ In this case, the handgrip strength is closely correlated to knee extensor muscle strength, regardless of age. ${ }^{27,28} \mathrm{~A}$ recent study discussed the question of whether or not the handgrip strength is a crucial tool as the knee extensor muscle strength and size for healthy young men. ${ }^{20}$ Furthermore, in a stepwise multiple-regression analysis, handgrip strength could not predict even knee extensor muscle MVIC in the present study. Taken together, these findings suggest that the handgrip strength may be particularly beneficial for evaluating the knee extensor muscle strength for middle-aged and older adults, but not for young men and women.

Our findings showed that upper leg 50\% girth was a major contributing factor to knee extensor muscle strength or size in healthy young women. This result was similar to that of a previously reported study for healthy young men..$^{20}$ Previously, some other studies have reported that upper leg $50 \%$ girth was not correlated with knee extensor muscle strength or size; therefore, these should not be used as indicators. ${ }^{29,30}$ This discrepancy might result from the different gender group used in the previous studies compared with our study. All subjects in the present study were women, whereas the previous studies had included both men and women (healthy subjects or patients). ${ }^{29,30}$ Consequently, our results suggested that, for healthy young women, upper leg 50\% girth measurement rather than handgrip strength test was a useful method for evaluating both knee extensor muscle strength and size.

In the present study, a stepwise multiple regression analysis was applied to the predictor standing long jump to predict knee extensor muscle strength, but not muscle size. This result was similar to that of a previously reported study for healthy young men. ${ }^{20}$ Whereas, another previous study reported that the standing long jump was related to leg press, but not to knee extensor muscle strength. ${ }^{31}$ In a linked-segment analysis and inverse dynamics methods study, ${ }^{18}$ the contributions of hip, knee, and ankle muscles were $45.9 \%, 3.9 \%$, and $50.2 \%$ for the standing long jump. In addition, the standing long jump test is an indicator of muscle power of the lower body, ${ }^{18,19}$ but it is difficult for older adults or for knee joint pain patients to perform this action due to the extreme pressure on the knee joint. Taken together, it appears that the standing long jump is limited to the evaluation of knee extensor muscle strength only for healthy young men and women. Furthermore, the standing long jump requires paying attention to the motor skill performance and the contribution of lower-extremity joint strength.

Previous studies reported that the sit-to-stand test can be a convenient measurement for assessment of the age-related decline in the knee extensor muscle strength, but not in the muscle size for older adults. ${ }^{15,17}$ However, there was no significant correlation between the sit-to-stand test and knee extensor muscle strength or size for young women as with young men. ${ }^{20}$ The $\mathrm{CV}$ tended to be lower in young individuals $\left(13.7 \%\right.$ for $\operatorname{men}^{20}$ and $20.6 \%$ for women) compared with previous studies in older adults $(26.0 \%$ for older adults, ${ }^{15} 19.2 \%-41.8 \%$ for older adults ${ }^{17}$ ), indicating that there was great variability in the sit-to-stand test capability among studies (young individuals vs older adults). Furthermore, the testretest reliability of the sit-to-stand measurement was poor compared with other measurements in this study. It can be speculated that the sit-to-stand test provides a reasonably reliable and valid indicator of knee extensor muscle strength in older adults, but not in young individuals regardless of gender.

The limitation of this study should be discussed. As the subjects were Japanese university freshmen women, the age distribution and the physical characteristics were very limited. Additional research is needed to address this issue.

\section{Conclusions}

Our results indicated that knee extensor muscle strength and size could be evaluated by the field-based simplified approaches, especially for the upper leg $50 \%$ girth measurement, which may be a major determinant to maintain an active life for healthy young women. However, the 4 field-based simplified approaches appear to be still not of high impact.

\section{Acknowledgments}

This study was supported, in part, by grant-in-aid (\#15K01553) from the Japan Ministry of Education, Culture, Sports, Science, and Technology and by Seirei Christopher University Grants-in-Aid of Research. The author declared no conflict of interest regarding the publication of this manuscript.

\section{References}

1. Guralnik JM, Simonsick EM, Ferrucci L, et al. A short physical performance battery assessing lower extremity function: association with self-reported disability and prediction of mortality and nursing home admission. J Gerontol. 1994;49:M85-M94. PubMed ID: 8126356 doi:10.1093/geronj/49.2.M85

2. Guralnik JM, Ferrucci L, Simonsick EM, Salive ME, Wallace RB. Lower-extremity function in persons over the age of 70 years as a predictor of subsequent disability. N Engl J Med. 1995;332:556-562. PubMed ID: 7838189 doi:10.1056/NEJM199503023320902

3. Stump TE, Clark DO, Johnson RJ, Wolinsky FD. The structure of health status among Hispanic, African American, and white older 
adults. J Gerontol B Psychol Sci Soc Sci. 1997;52:49-60. PubMed ID: 9215357 doi:10.1093/geronb/52B.Special_Issue.49

4. Hunter SK, Thompson MW, Adams RD. Relationships among ageassociated strength changes and physical activity level, limb dominance, and muscle group in women. J Gerontol A Biol Sci Med Sci. 2000;55:B264-B273. PubMed ID: 10843342 doi:10.1093/gerona/ 55.6.B 264

5. Janssen I, Heymsfield SB, Wang ZM, Ross R. Skeletal muscle mass and distribution in 468 men and women aged 18-88 yr. J Appl Physiol. 2000;89:81-88. PubMed ID: 10904038 doi:10.1152/jappl. 2000.89.1.81

6. Miyatani M, Kanehisa H, Azuma K, Kuno S, Fukunaga T. Siterelated differences in muscle loss with aging "A cross-sectional survey on the muscle thickness in Japanese men aged 20 to 79 years". Int J Sport Health Sci. 2003;1:34-40. doi:10.5432/ijshs.1.34.

7. Abe T, Sakamaki M, Yasuda T, et al. Age-related, site-specific muscle loss in 1507 Japanese men and women aged 20 to 95 years. J Sports Sci Med. 2011;10:145-150. PubMed ID: 24149307

8. Abe T, Patterson KM, Stover CD, et al. Site-specific thigh muscle loss as an independent phenomenon for age-related muscle loss in middleaged and older men and women. Age (Dordr). 2014;36:9634. doi: 10.1007/s11357-014-9634-3.

9. Kallman DA, Plato CC, Tobin JD. The role of muscle loss in the agerelated decline of grip strength: cross-sectional and longitudinal perspectives. J Gerontol. 1990;45:M82-M88. PubMed ID: 2335723 doi:10.1093/geronj/45.3.M82

10. Abe T, Loenneke JP. Handgrip strength dominance is associated with difference in forearm muscle size. J Phy Ther Sci. 2015;27: 2147-2149. doi:10.1589/jpts.27.2147.

11. Martien S, Delecluse C, Boen F, et al. Is knee extension strength a better predictor of functional performance than handgrip strength among older adults in three different settings? Arch Gerontol Geriatr. 2015;60:252-258. PubMed ID: 25496605 doi:10.1016/j.archger. 2014.11.010

12. Taekema DG, Gussekloo J, Maier AB, Westendorp RG, de Craen AJ. Handgrip strength as a predictor of functional, psychological and social health. A prospective population-based study among the oldest old. Age Ageing. 2010;39:331-337. PubMed ID: 20219767 doi:10. 1093/ageing/afq022

13. Housh DJ, Housh TJ, Weir JP, Weir LL, Johnson GO, Stout JR. Anthropometric estimation of thigh muscle cross-sectional area. Med Sci Sports Exerc. 1995;27:784-791. PubMed ID: 7674885 doi:10. 1249/00005768-199505000-00023

14. Chen BB, Shih TT, Hsu CY, et al. Thigh muscle volume predicted by anthropometric measurements and correlated with physical function in the older adults. J Nutr Health Aging. 2011;15:433-438.

15. Jones CJ, Rikli RE, Beam WC. A 30-s chair-stand test as a measure of lower body strength in community-residing older adults. Res $Q$ Exerc Sport. 1999;70:113-119. PubMed ID: 10380242 doi:10.1080/ 02701367.1999.10608028

16. Yamada T, Demura S. The relationship of force output characteristics during a sit-to-stand movement with lower limb muscle mass and knee joint extension in the elderly. Arch Gerontol Geriatr. 2010;50:e46-e50. PubMed ID: 19552969 doi:10.1016/j.archger. 2009.05.009
17. Kanehisa H, Fukunaga T. Age-related change in sit-to-stand power in Japanese women aged 50 years or older. J Physiol Anthropol. 2014;33:26. doi:10.1186/1880-6805-33-26

18. Robertson DG, Fleming D. Kinetics of standing broad and vertical jumping. Can J Sport Sci. 1987;12:19-23. PubMed ID: 3594313

19. Almuzaini KS, Fleck SJ. Modification of the standing long jump test enhances ability to predict anaerobic performance. J Strength Cond Res. 2008;22:1265-1272. PubMed ID: 18545179 doi:10.1519/JSC. Ob013e3181739838

20. Yasuda T, Ichikawa D. Field-based simplified approach of evaluating knee extensor muscle strength and size in male university freshmen. J Sports Sci. 2016;4:272-278.

21. Yamada M, Nishiguchi S, Fukutani N, et al. Prevalence of sarcopenia in community-dwelling Japanese older adults. J Am Med Dir Assoc. 2013;14:911-915. PubMed ID: 24094646 doi:10.1016/j.jamda.2013. 08.015

22. Abe T, Kawakami Y, Suzuki Y, Gunji A, Fukunaga T. Effects of 20 days bed rest on muscle morphology. J Gravit Physiol. 1997;4: S10-S14. PubMed ID: 11541170

23. Abe T, Kondo M, Kawakami Y, Fukunaga T. Prediction equations for body composition of Japanese adults by B-mode ultrasound. Am J Hum Biol. 1994;6:161-170. doi:10.1002/ajhb.1310060204

24. Ogawa M, Mitsukawa N, Bemben MG, Abe T. Ultrasound assessment of adductor muscle size using muscle thickness of the thigh. J Sport Rehabil. 2012;21:244-248. PubMed ID: 22713209 doi: 10.1123/jsr.21.3.244

25. Yasuda T, Fukumura K, Nakajima T. Short physical performance battery for middle-aged and older adult cardiovascular disease patients: implication for strength tests and lower extremity morphological evaluation. J Phys Ther Sci. 2017;29:748-753. PubMed ID: 28533623 doi:10.1589/jpts. 29.748

26. Johnson MJ, Friedl KE, Frykman PN, Moore RJ. Loss of muscle mass is poorly reflected in grip strength performance in healthy young men. Med Sci Sports Exerc. 1994;26:235-240. PubMed ID: 8164542 doi:10.1249/00005768-199402000-00015

27. Lauretani F, Russo CR, Bandinelli S, et al. Age-associated changes in skeletal muscles and their effect on mobility: an operational diagnosis of sarcopenia. J Appl Physiol. 2003;95:1851-1860. PubMed ID: 14555665 doi:10.1152/japplphysiol.00246.2003

28. Cruz-Jentoft AJ, Baeyens JP, Bauer JM, et al. Sarcopenia: European consensus on definition and diagnosis: report of the European Working Group on Sarcopenia in older people. Age Ageing. 2010;39: 412-423. PubMed ID: 20392703 doi:10.1093/ageing/afq034

29. Arangio GA, Chen C, Kalady M, Reed JF 3rd. Thigh muscle size and strength after anterior cruciate ligament reconstruction and rehabilitation. J Orthop Sports Phys Ther. 1997;26:238-243. PubMed ID: 9353686 doi:10.2519/jospt.1997.26.5.238

30. Mathur S, Takai KP, Macintyre DL, Reid D. Estimation of thigh muscle mass with magnetic resonance imaging in older adults and people with chronic obstructive pulmonary disease. Phys Ther. 2008;88:219-230. PubMed ID: 18056754 doi:10.2522/ptj.20070052

31. Blackburn JR, Morrissey MC. The relationship between open and closed kinetic chain strength of the lower limb and jumping performance. J Orthop Sports Phys Ther. 1998;27:430-435. PubMed ID: 9617729 doi:10.2519/jospt.1998.27.6.430 